\title{
EFFECT OF THE ADDITION OF LI ON THE STRUCTURE AND MECHANICAL PROPERTIES OF HYPOEUTECTIC $\mathrm{Al}-\mathrm{Mg}_{2} \mathrm{Si}$ ALLOYS
}

\author{
Olena Prach ${ }^{a, *}$, Jakub Hornik ${ }^{b}$, Kostiantyn Mykhalenkov $^{a}$ \\ a National Technical University of Ukraine "KPI", Polytechnichna St. 35, Building 9, 03056, Kiev, Ukraine \\ ${ }^{b}$ Czech Technical University in Prague, Karlovo náměstí 13, 12135, Prague 2, Czech Republic \\ * corresponding author: elena.prach@gmail.com
}

ABstract. Alloys with various contents of Li were studied by means of differential scanning calorimetry (DSC), transmission electron microscopy (TEM) and energy dispersive X-Ray microanalysis (EDX). The TEM investigations revealed that three different types of precipitation are formed in the alloy matrix during artificial aging. Two of the types represent different morphologies of $\mathrm{Mg}_{2} \mathrm{Si}$ precipitates. The appearance of the third type, identified as the $\delta-\mathrm{Al}_{3} \mathrm{Li}$ phase, shows that the Al-Mg-Si system can be used successfully for designing an Li-containing casting alloy. However, this alloy has not yet been developed.

KEYWORDS: cast Al-Mg-Si alloys; Li addition; DSC; nanosize precipitation microscopy.

\section{INTRODUCTION}

Al-Mg-Si casting alloys possess good corrosion resistance, weldability, high surface finishing quality and, in a particular case, extremely high mechanical properties in as-cast condition. It was reported by Koch et al. [1] that an Al-alloy with the nominal composition $\mathrm{AlMg}_{5} \mathrm{Si}_{2} \mathrm{Mn}$, subjected to high pressure die casting (HPDC), has levels of ductility (up to $18 \%$ ), yield strength (up to $220 \mathrm{MPa}$ ) and ultimate tensile strength (up to $350 \mathrm{MPa}$ ) that are higher than those of other casting alloys.

It can be deduced from Jiang et al. [2] that the ultimate tensile strength of A356 T6 may reach a level up to $300 \mathrm{MPa}$ and elongation to fracture of $6 \%$. The mechanical properties achieved with permanent mold casting of $\mathrm{AlMg}_{5} \mathrm{Si}_{2} \mathrm{Mn}$ are comparable with the properties of A356 [3]. It was found that the ultimate tensile strength varies from 255 to $298 \mathrm{MPa}$, and the elongation is in the range from 1.2 and $3.2 \%$. It should be noted that these low elongation values are one order lower than the values for $\mathrm{AlMg}_{5} \mathrm{Si}_{2} \mathrm{Mn}$ HPDC, where the level can be as high as $18 \%$.

It is known that the Al-Mg-Si system belongs to the group of age hardenable alloys, and heat treatment can be used to achieve necessary conditions with appropriate strength [4, 5]. However, the optimal solution, e.g. treatment temperature, and the time for artificial ageing of the casting alloys, has not yet been established.

Similarly as for heat treatment, the effect of additional alloying of $\mathrm{AlMg}_{5} \mathrm{Si}_{2} \mathrm{Mn}$, for example with $\mathrm{Li}$, on the formation of the structure and on the mechanical properties, has also not yet been investigated. From the early work of Fridlyander et al. [6], it is clear that the addition of $\mathrm{Li}$ to $\mathrm{Al}-\mathrm{Cu}$ or $\mathrm{Al}-\mathrm{Mg}$ alloys can substantially enhance the mechanical properties, while at the same time decreasing the density. There has been a strong advance in the development of Al$\mathrm{Cu}-\mathrm{Li}$ and $\mathrm{Al}-\mathrm{Mg}-\mathrm{Li}$ wrought alloys in recent years. However, no Li-containing casting alloy has yet been designed. A proposal has been put forward to use the $\mathrm{AlMg}_{5} \mathrm{Si}_{2} \mathrm{Mn}$ casting alloy as the matrix for the design of a Li-containing casting alloy with various contents of $\mathrm{Mg}$, and to reveal the effect of $\mathrm{Mg}$ and $\mathrm{Li}$ on the structure of the alloys and on the precipitation of the strengthening phases.

The main scientific approach to the addition of $\mathrm{Li}$ is based on the composition of an $\alpha$-Al solid solution in $\mathrm{AlMg}_{5} \mathrm{Si}_{2} \mathrm{Mn}$. During preliminary investigations, measurements showed that $\alpha$-Al grains contain about 2.4 at\% Mg, 0.3-0.4 at\% Mn, and no Si content was detected. Hence $\alpha$-Al grains of $\mathrm{AlMg}_{5} \mathrm{Si}_{2} \mathrm{Mn}$ can be considered similarly to $\alpha-\mathrm{Al}$ grains in $\mathrm{Al}-\mathrm{Mg}$ alloy, where the addition of $\mathrm{Li}$ produces a strengthening effect. The purpose of the present work is to establish the melting behavior of the Al-Mg-Si-Mn casting alloy with various contents of $\mathrm{Mg}$, and to find out the effect of $\mathrm{Li}$ on the microstructure and the hardness of the alloy.

\section{MATERIAL AND METHODS}

The chemical compositions of the alloys under consideration here are presented in Tab. 1. Commercial casting alloy A356 was used for the purposes of comparison.

All alloys were prepared in an electric resistant furnace using graphite crucibles. $\mathrm{AlMg}_{50}, \mathrm{AlSi}_{25}, \mathrm{AlMn}_{26}$ and high-purity aluminum $\left(\mathrm{Al}_{99.997}\right)$ were used as master alloys. The melt at a temperature of $720 \pm 5{ }^{\circ} \mathrm{C}$ had been degassed under an argon atmosphere for 10 minutes. Two types of heat treatment were applied. The first type was solution treatment, which was con- 


\begin{tabular}{lcccccc}
\hline Alloy & Mg & Si & Mn & Li & Fe \\
\hline \multicolumn{5}{c}{ Experimental alloys in } & wt\% \\
\hline L & 4.79 & 2.23 & 0.5 & 1 & 0.03 \\
LL & 3.27 & 3.08 & 0.62 & 0.5 & 0.02 \\
\hline \multicolumn{5}{c}{ Commercial alloys in } & wt\% \\
\hline B2 & 7 & 3 & 0.6 & 1 & - \\
A356 & 0.32 & 6.97 & 0.02 & - & 0.06 \\
\hline
\end{tabular}

TABLE 1. Nominal composition of alloys (Al-balance)

ducted in an electric resistance furnace at $570{ }^{\circ} \mathrm{C}$. After solution treatment, the specimens were quenched in water at room temperature. The second type of heat treatment was $\mathrm{T} 6$, which combines treatment of the solution at a temperature of $570^{\circ} \mathrm{C}$, cooling in water and artificial aging at $175^{\circ} \mathrm{C}$ for various periods of time. The specimens were taken out of the furnace and were cooled in still air after artificial ageing.

Samples for microstructure observations in a scanning electron microscope (SEM) were prepared using conventional metallographic techniques. The composition of the phases was measured by EDX analysis, using SEM. All TEM investigations were carried out using a Philips CM 30 TEM, operated at $250 \mathrm{kV}$ accelerating voltage and equipped with the Energy Dispersive Spectrometry system (EDX) by the Thermo Scientific Noran System. Thin foils were prepared using an electrolytic thinning technique.

A NETZSCH DSC 404 differential scanning calorimeter was used for an investigation of the specific temperatures associated with the melting of the different phases. The heating rates were within the range of $1-20 \mathrm{~K} / \mathrm{min}$.

Hardness measurements were performed using a Brinell hardness testing machine (HB) with a ball $2.5 \mathrm{~mm}$ in diameter and a load of $62.5 \mathrm{~kg}$. The time of loading was 10 seconds. HV 0.05 microhardness tests were applied to polished non-etched specimens on a Duramin-2 microhardness tester, with a standard indentation time. Tensile tests were carried out using the INSTRON 5582 testing machine according to the EN ISO 6892-1 standard, on normalized specimens.

\section{Results AND Discussion}

Differential scanning calorimetry. The curves of the changes in the heat flow in dependence on temperature for representative alloys (with different cooling/heating rates) and commercial alloys are shown in Figs. 1 and 2 The thermal effects were not observed in the temperature range from $20-590^{\circ} \mathrm{C}$, so this temperature range is not shown here.

When the temperature reaches close to $590^{\circ} \mathrm{C}$, a negative thermal effect occurs on the heating curve, which corresponds to the endothermic reaction. The observed effect is characterized by the following temperatures:

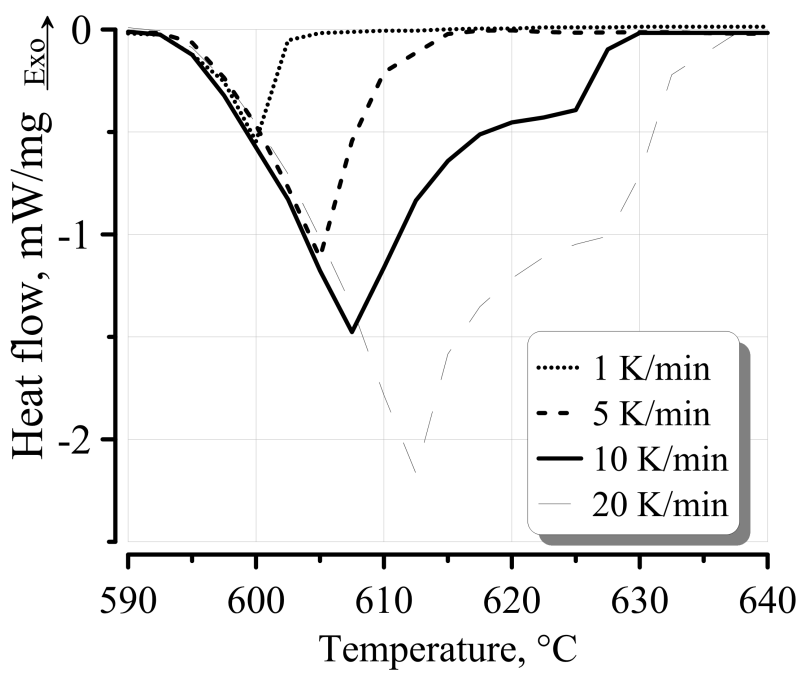

Figure 1. DSC curves of the $\mathrm{T}$ alloy at various heating and cooling rates.

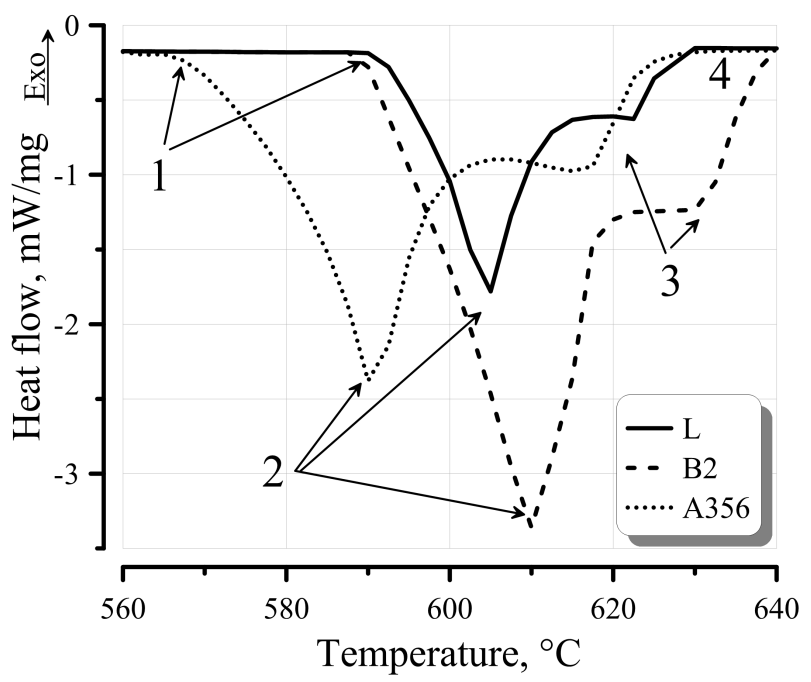

Figure 2. DSC curves of commercial Al-alloys (cooling rate $10 \mathrm{~K} / \mathrm{min}$ ).

- $\mathrm{T}_{\text {onset }}$ - melting temperature of the eutectic (denoted 1),

- $\mathrm{T}_{\text {peak }, 1}$ - temperature of peak 1 (denoted 2$)$,

- $\mathrm{T}_{\text {peak,2 }}$ - temperature of peak 2 (denoted 3$)$,

- $\mathrm{T}_{\text {outset }}$ - end of the thermal effect (denoted 4) (Fig. 2).

Figure 1 illustrates the DSC heating curves recorded at various heating rates of $1,5,10$ and $20 \mathrm{~K} / \mathrm{min}$ for the L alloy in comparison with the heating curve for the commercial A356 alloy. For slow heating (1 and $5 \mathrm{~K} / \mathrm{min}$ ), the thermal effects are depressed, and four sharp endothermic reactions can be distinguished only when a $10 \mathrm{~K} / \mathrm{min}$ heating rate is used. The first thermal reaction during heating is clearly visible in Fig. 2 and is denoted as 1 . This is an endothermic effect with the peak onset of $571{ }^{\circ} \mathrm{C}$ observed in the heating curve for the A356 commercial alloy. This corresponds to the melting of $(\mathrm{Al})+(\mathrm{Si})$ eutectic. This value is 


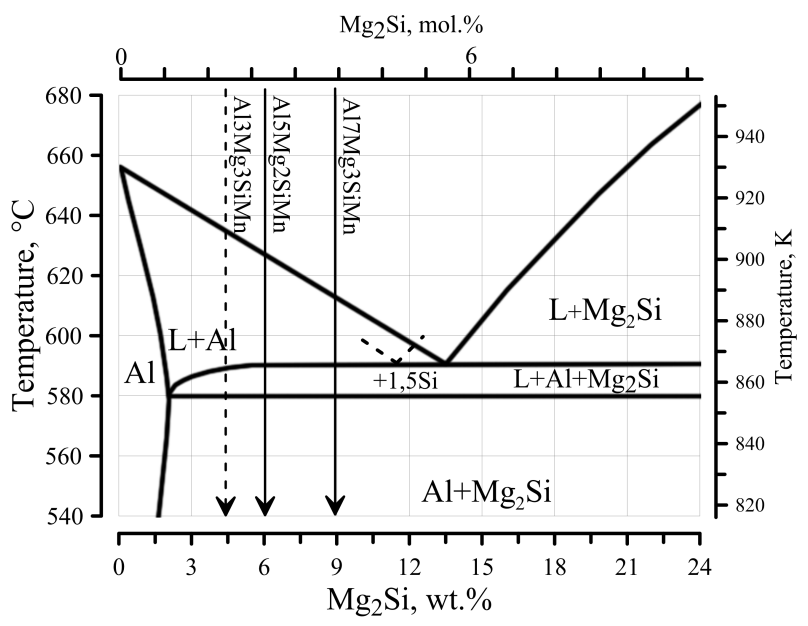

Figure 3. Phase diagram of the $\mathrm{Al}-\mathrm{Mg}_{2} \mathrm{Si}$ system (according to a literature review).

very close to that defined from the equilibrium Al-Si binary phase diagram, where the eutectic undergoes melting at $577^{\circ} \mathrm{C}$ 4.

For the L and B alloys, the DSC tests show the first endothermic peaks at about $595{ }^{\circ} \mathrm{C}$ (denoted 2$)$, which corresponds to the melting of eutectic $(\mathrm{Al})+\left(\mathrm{Mg}_{2} \mathrm{Si}\right)$. The experimentally measured value coincides absolutely with the data for the equilibrium ternary AlMg-Si phase diagram [7]. The heat effect 2 detected in the B2 alloy is much larger than the effect for $\mathrm{L}$.

Further heating led to the appearance of another endothermic peak, which is attributed to the melting of $\alpha$-Al (denoted 3). The $\alpha$-Al melting temperatures were found to be very close for the A356, B2 and L alloys. For the end of melting, denoted 4 , the $\mathrm{T}_{\text {outset }}$ temperatures of about $630^{\circ} \mathrm{C}$ are very similar for all alloys.

In order to explain these effects, the DSC data was compared with the phase diagram of $\mathrm{Al}-\mathrm{Mg}_{2} \mathrm{Si}$ (Fig. 3). The DSC results for the commercial $\mathrm{Al}_{5} \mathrm{Mg}_{2} \mathrm{SiMn}$ alloy correspond fully with the results obtained for the samples of L alloys. This demonstrates that the addition of $1 \mathrm{wt} \%$ of $\mathrm{Li}$ has no effect on the type of melting and solidification of the Al-Mg-Si-Mn system casting alloys.

The results of the DSC investigation are summarized in Tab. 2. A comparison of the DSC results shows that the eutectic melting temperature found for L and B2 alloys are very close to each other, but are considerably higher than the eutectic melting temperature for the A356 alloy. This means that the service temperature of Al-Mg-Si casting alloys may be higher than the service temperature of the commercial casting alloys that are now in use. For confirmation, however, it is necessary to carry out a series of mechanical property tests at various temperatures. The addition of $\mathrm{Li}$ has no effect on the eutectic melting temperature.

\begin{tabular}{cllll}
\hline Denoted & DSC & A356 & \multicolumn{1}{c}{ L } & B2 \\
\hline 1 & $\mathrm{~T}_{\text {onset }}$ & 571 & 594.3 & 595 \\
2 & $\mathrm{~T}_{\text {peak }, 1}$ & 590 & 605 & 610 \\
3 & $\mathrm{~T}_{\text {peak }, 2}$ & 617.5 & 620.8 & 620.3 \\
4 & $\mathrm{~T}_{\text {outset }}$ & 622.7 & 630 & 637.6 \\
\hline
\end{tabular}

TABle 2. Temperature characteristics of heat effects observed during heating.

Microstructure investigation. The structures of the base alloy before and after alloying with $\mathrm{Li}$ are shown in Fig. 4 All alloys exhibit an equiaxed grain structure, and five phase constituents can be distinguished, i.e.: an $\alpha$-Al solid solution (gray, denoted 1); $(\mathrm{Al})+\left(\mathrm{Mg}_{2} \mathrm{Si}\right)$ eutectic (dark, denoted 2$) ; \mathrm{Mg}_{2} \mathrm{Si}$ primary crystals (dark, denoted 3 ); $\alpha-\mathrm{Al}_{12}(\mathrm{Mn}, \mathrm{Fe})_{3} \mathrm{Si}$ phase (white, denoted 4); globular Al-Si phase (grey, denoted 5, only in LL alloy).

The preferential morphology of $\alpha$-Al follows a dendritic structure, with long primary arms for all alloys. The $(\mathrm{Al})+\left(\mathrm{Mg}_{2} \mathrm{Si}\right)$ eutectic has a lamellar morphology, where long $\mathrm{Mg}_{2} \mathrm{Si}$ plates alternate with $\alpha$-Al. The primary $\mathrm{Mg}_{2} \mathrm{Si}$ crystals have a regular polyhedral shape and are situated in the centres of eutectic colonies. The addition of Li produces a modified effect.

During solution treatment, the phase composition of the alloys remains the same as in the as-cast condition, but it changes the morphology of the phases. During heating at $570{ }^{\circ} \mathrm{C}$, lamellas of $\mathrm{Mg}_{2}$ Si rapidly spherodize (Fig. 4 bd) [8].

Elements of Distribution. $\alpha$-Al grain. The composition of the matrix of all alloys varies slightly. The $\alpha$-Al solid solution of all alloys contains $\mathrm{Mg}, \mathrm{Si}$ and Mn. It is known that the solubility of magnesium in aluminium amounts to $1.4 \%$, and the solubility of silicon amounts to $0.4 \%$, at room temperature. The $\mathrm{Mg}$ content in a solid solution measured in SEM using $15 \mathrm{kV}$ acceleration voltage is $2.4 \mathrm{wt} \%$. The $\mathrm{Mg}$ distribution across the dendrite arm is not homogeneous, and varies in the range from 2.3 to $2.6 \mathrm{wt} \%$. For all alloys, the $\mathrm{Mn}$ content in an $\alpha$-Al solid solution is $0.5 \mathrm{wt} \%$. The small Si content measured for the SEM EDX analysis obviously originated from the surrounding $\mathrm{Mg}_{2} \mathrm{Si}$ lamellas, or from lamellas lying beneath the surface. The Si concentration in the $\alpha$-Al grains of all alloys was less than $0.4 \mathrm{wt} \%$.

Eutectic. The stoichiometric composition of $\mathrm{Mg}_{2} \mathrm{Si}$ is $66.7 \mathrm{at} \% \mathrm{Mg}$ and $33.3 \mathrm{at} \% \mathrm{Si}$ (the $\mathrm{Mg} / \mathrm{Si}$ at. ratio is 2.0 , and the weight ratio is $1.73: 1)$. When the ratio is more than $1.73, \mathrm{Mg}$ is prevalent, and when the ratio is less than $1.73, \mathrm{Si}$ is prevalent. The EDX spectra of the lamellas excluding the $\mathrm{Al}$ from quantification provided a composition of the eutectic lamellas very close to the stoichiometry of $\mathrm{Mg}_{2} \mathrm{Si}$, namely $\mathrm{Mg} 62.5$ at\% and Si $31.2 \mathrm{at} \%$. The EDX spectra of the interlamellar space showed a high concentration of $\mathrm{Mg}$ and $\mathrm{Si}$. 


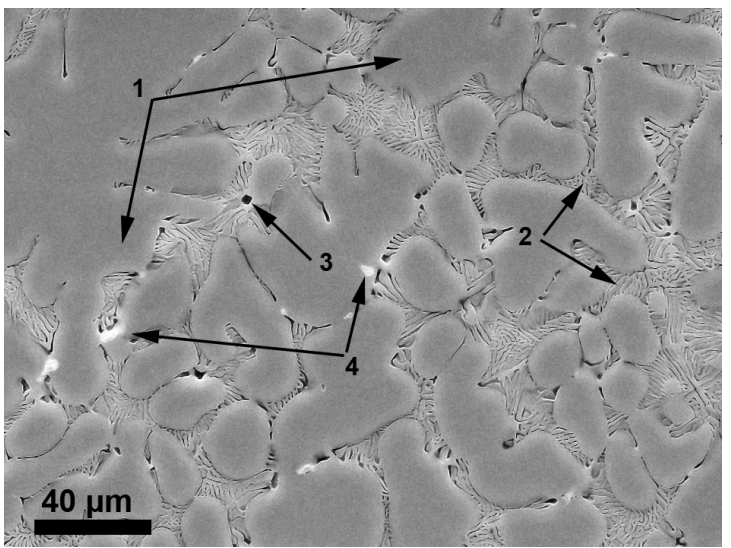

(a)

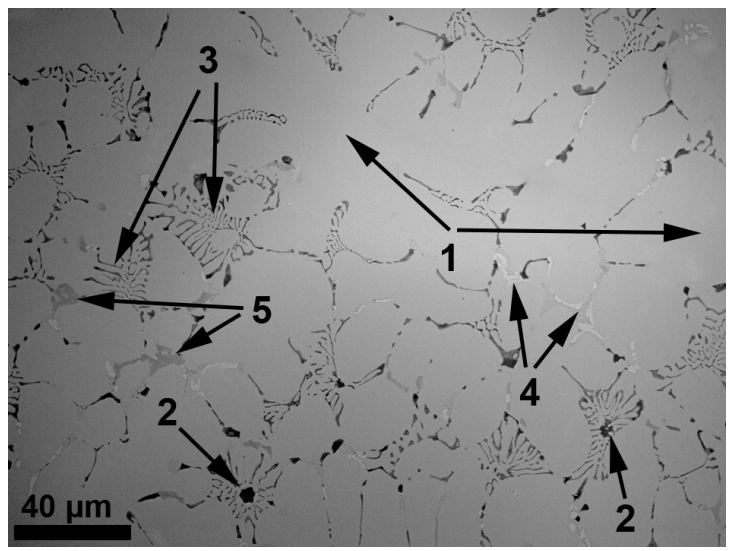

(c)

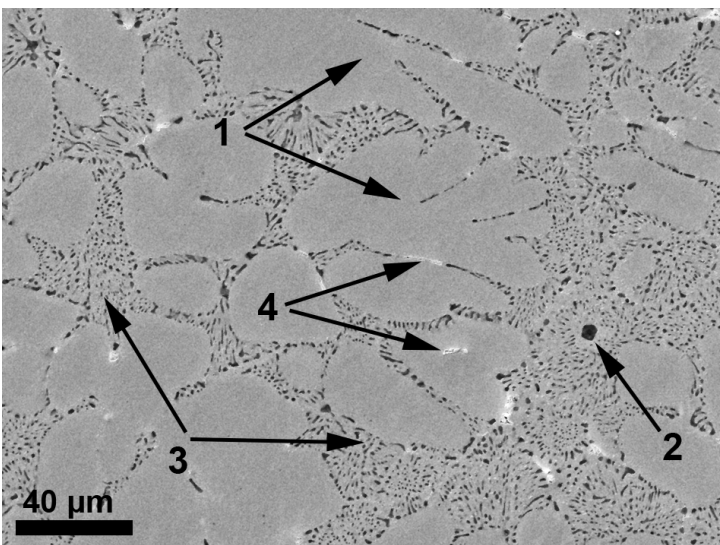

(b)

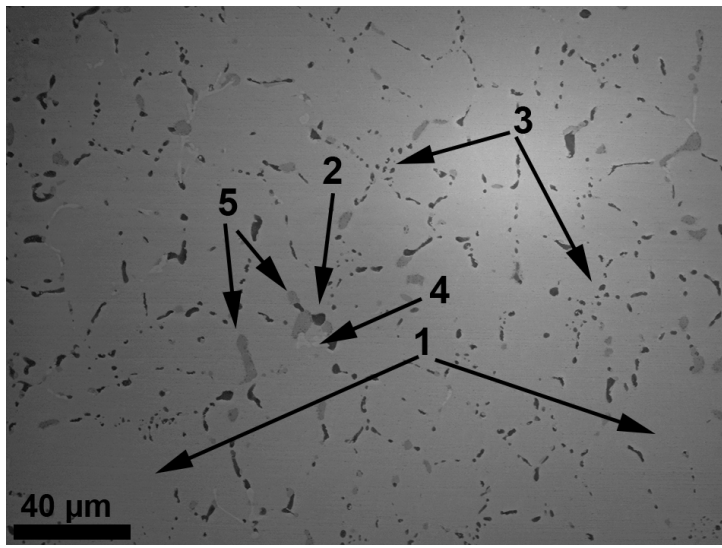

(d)

Figure 4. Microstructure of the investigated alloys: (a) L-series, as-cast state; (b) L-series, solution treated; (c) LL-series, as-cast state; (d) LL-series, solution treated.

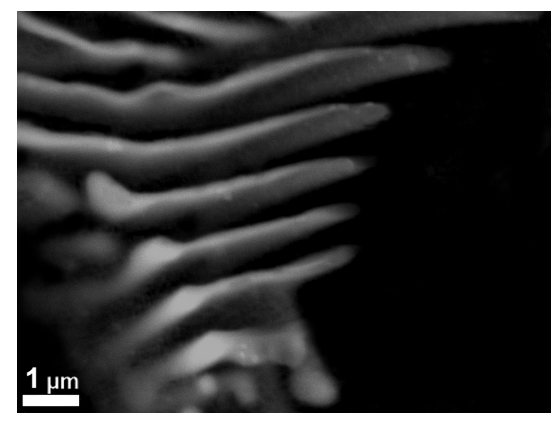

(a)

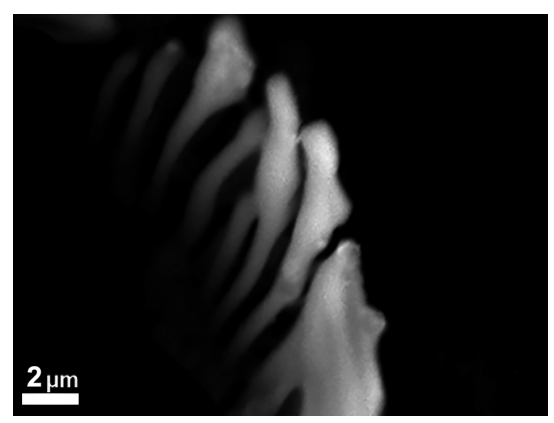

(b)

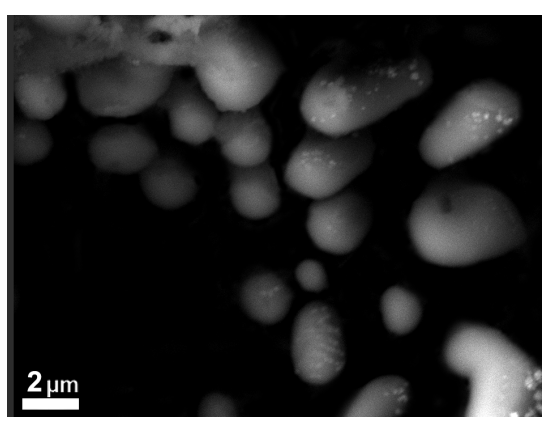

(c)

Figure 5. Morphologies of the $(\mathrm{Al})+\left(\mathrm{Mg}_{2} \mathrm{Si}\right)$ eutectic in the A356 alloy (a); L alloy (b); after solution treatment (c).

The $(\mathrm{Al})+\left(\mathrm{Mg}_{2} \mathrm{Si}\right)$ eutectic in A356 has a lamellar morphology, where long $\mathrm{Mg}_{2} \mathrm{Si}$ plates alternate with $\alpha$-Al (Fig. 5a). After the addition of Li, the eutectic becomes fibrous, as in Fig. 5] [9]. When the solution is treated at $575^{\circ} \mathrm{C}$, the lamellas of $\mathrm{Mg}_{2} \mathrm{Si}$ rapidly form separate spheres (Fig. 50). A model of the spheroidization of eutectic lamellas and fibres in alloys of the Al-Mg-Si system is presented in [8].

Mn-containing phase. Due to poor solubility, iron with silicon and aluminium in Al-Mg-Si alloys contains acicular-shaped intermetallic inclusions, which reduce the strength and the ductility of the alloys. To neutralize the negative effect [13] of the Fe-containing phase, the alloys investigated here are additionally doped with $0.6 \% \mathrm{Mn}$. According to the amount of excess silicon, manganese and iron in the evaluated alloys, several types of manganese phase are formed: $\left(\mathrm{Al}_{6}(\mathrm{Mn}, \mathrm{Fe}), \quad \mathrm{Al}_{8}(\mathrm{Mn}, \mathrm{Fe}), \quad \alpha-\mathrm{Al}_{15}(\mathrm{Mn}, \mathrm{Fe})_{3} \mathrm{Si}_{2}, \quad \beta-\right.$ $\left.\mathrm{Al}_{5}(\mathrm{Mn}, \mathrm{Fe}) \mathrm{Si}, \delta-\mathrm{Al}_{4}(\mathrm{Mn}, \mathrm{Fe}) \mathrm{Si}_{2}\right)$ [10, 11].

Previous studies have shown that the addition of $0.6 \mathrm{wt} \%$ of $\mathrm{Mn}$ to the alloy with a stoichiometric ratio of $\mathrm{Mg}$ : Si close to 2 : 1 improves its mechanical properties. Thus, the tensile strength and the yield strength of the alloy increase by $30 \%$, on average, with the addition of manganese. 


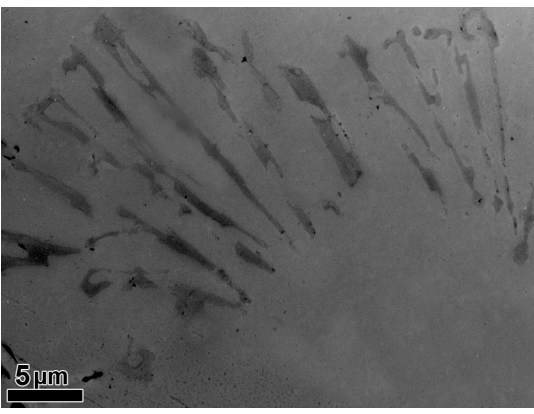

(a)

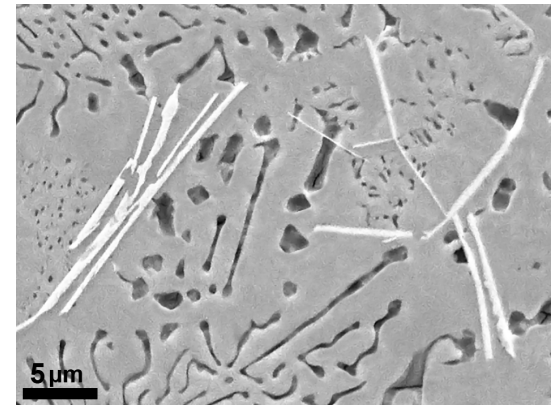

(b)

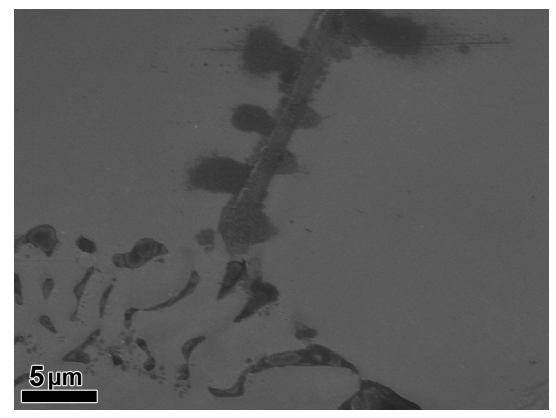

(c)

Figure 6. Morphology $\mathrm{Si}$ - content phases: (a) Al-Si eutectic in an alloy with extra $\mathrm{Si}$; (b) $\delta$ - $\mathrm{Al}_{4}\left(\mathrm{Mn}_{2}, \mathrm{Fe}\right) \mathrm{Si}_{2}$ phase in an alloy with extra $\mathrm{Si}$ and extra $\mathrm{Mn}$; (c) Al-Si phase in an alloy with extra Si modified by Li.

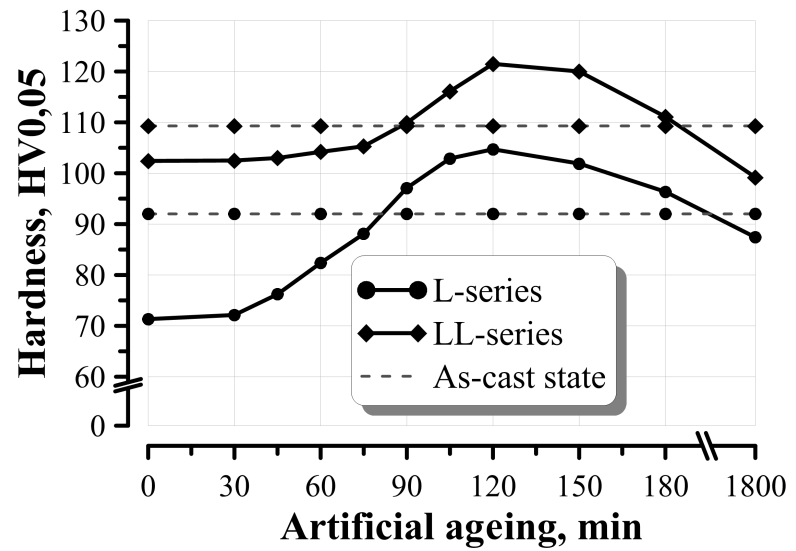

(a)

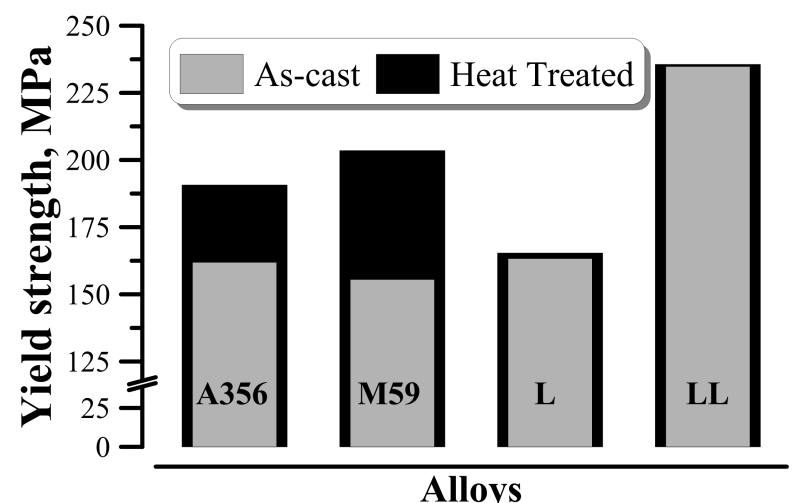

(c)

FiguRE 7. Mechanical properties: (a) macrohardness, (b) microhardness, (c) tensile strength, (d) yield strength.

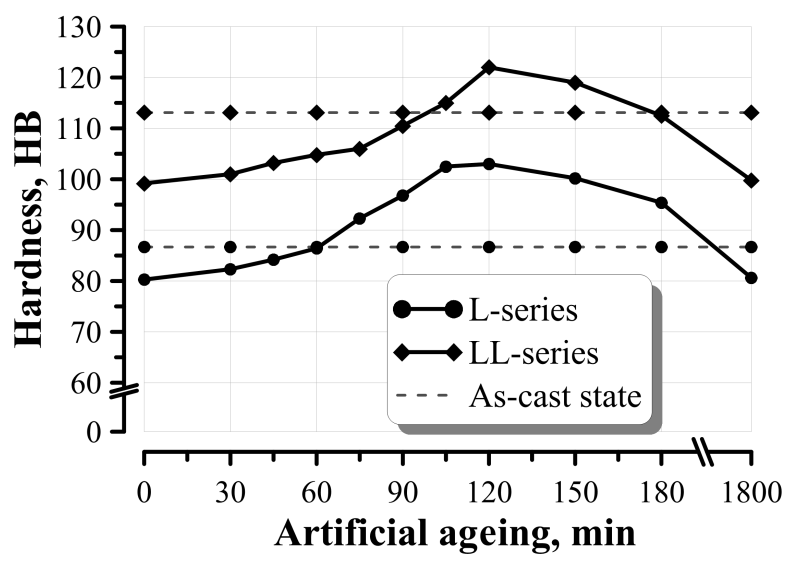

(b)

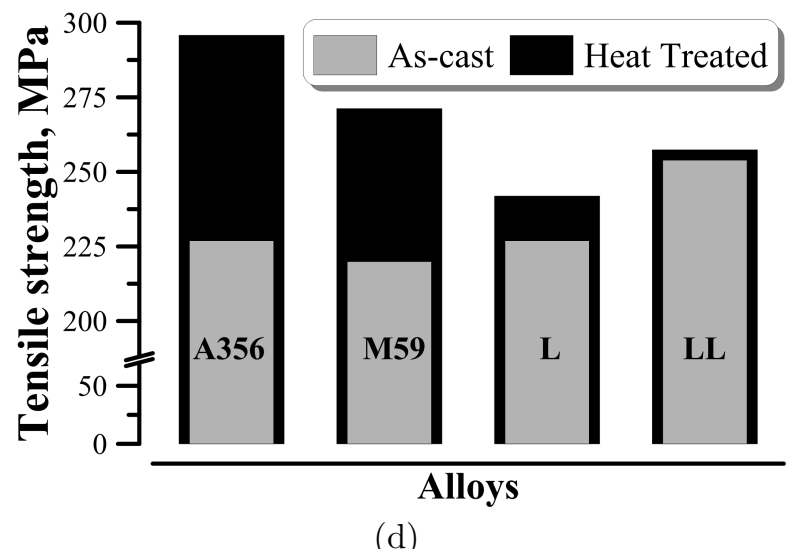

(d)
Modification effect of Li. Generally, there are two possible mechanisms for influencing the structural formation of alloys. One of these is the influence of modifiers on the solidification front, i.e. changing the surface energy of the growing crystals. The second mechanism is based on heterogeneous nucleation, i.e. the alloying components serve as nucleating particles $[12$.

Adding lithium to aluminum alloys is an example of the first of these mechanisms. A change in the surface energy of the $\mathrm{Mg}_{2} \mathrm{Si}$ crystals, caused by $\mathrm{Li}$ atoms on its surface or entering its lattice, may also be responsible for the change in the growth morphology [13]. The volume fraction of $\alpha$-Al increased with increasing
Li content, but the eutectic areas were appreciably reduced. The appearance of the larger grains may be a consequence of the wider ternary range in the diagram [13. The authors of [13] hypothesized that the addition of Li shifted the eutectic point towards the $\mathrm{Mg}_{2} \mathrm{Si}$ rich side of the diagram, but the authors of [14] reported that the addition of $\mathrm{Li}$ shifted the eutectic point towards the $\alpha$-Al rich side of the diagram.

Fig. 5 b shows that the Li-free alloy had a lamellar morphology, and that the addition of Li changes it to a fibrous shape. Fig. 6 presents how Li influences the Si-content phases in alloys, with a different content of extra Si and extra Mn changing it from a rod-like shape to a globular shape. 


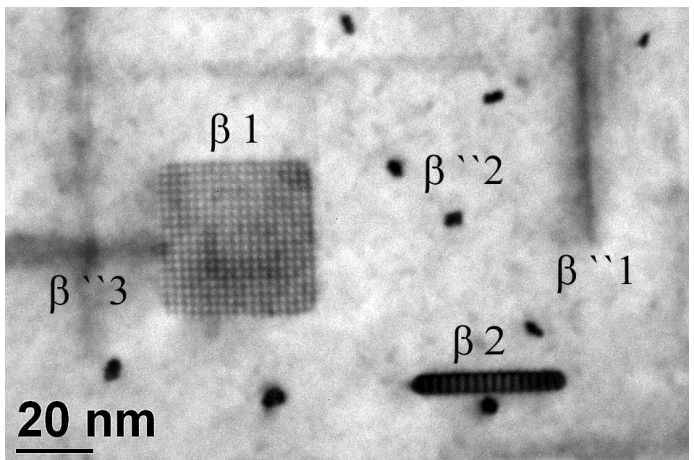

(a)

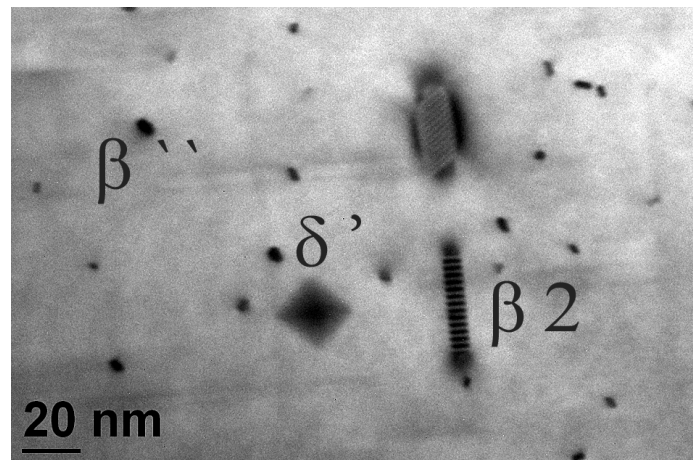

(b)

FiguRE 8. Bright field image of $\beta-\mathrm{Mg}_{2} \mathrm{Si}$ cuboid particles and $\beta^{\prime \prime}$ needles $(\mathrm{a}) ; \delta^{\prime}-\mathrm{Al}_{3} \mathrm{Li}$ phase in the $\mathrm{L}$ alloy after artificial ageing at $175^{\circ} \mathrm{C}$ for $30 \mathrm{~h}$.

Mechanical properties. The results of hardness and tensile tests are summarized in Fig. 7. The treatment of the solution results in a significant decrease in both the HB values and the HV 0.05 values. In addition, artificial ageing increases all mechanical properties of alloys. The changes during heat treatment are the result of eutectic spheroidization (Fig. 4). A higher solution treatment temperature leads to faster decomposition of eutectic lamellas into smaller segments, and to the spheroidizing effect [8]. This process decreases the hardness of the alloys.

Literature data 15 17. and a preliminary study showed that the mechanical properties of $\mathrm{Al}-\mathrm{Mg}_{2} \mathrm{Si}$ Si alloys are improved with an increased amount of silicon (and with an increased volume fraction of AlSi eutectic). However, extra silicon with manganese can form metastable phases, which deteriorates the properties (increases the brittleness) of the alloys in as-cast state. The modifying effect of Li fixes extra $\mathrm{Si}$, and forms a globular Al-Si phase in the LL alloy. The test results (Fig. 7) show that heat treatment of the alloys with extra silicon improves the mechanical properties. With increasing time of artificial ageing (at $175^{\circ} \mathrm{C}$ ), the hardness of the alloys grows with extra silicon. This can be explained by a sufficient amount of silicon in solid solution to form a larger number of strengthening particles.

TEM observation. After the hardness and microhardness measurements, the artificially aged specimens were subjected to a TEM investigation. The main task was to analyze the composition of the solid solution and to detect precipitates formed via decomposition of the supersaturated solid solution.

Fig. 8 shows TEM bright field images of the L alloy artificially aged at $175^{\circ} \mathrm{C}$ for 30 hours. Three morphologies of the precipitates can be clearly distinguished. The first morphology is represented by the long needles lying in perpendicular directions and marked as $\beta_{1}^{\prime \prime}$ and $\beta_{3}^{\prime \prime}$. Fine black spots, marked as $\beta_{2}^{\prime \prime}$, are the transverse section of the needles. These precipitates are the $\beta^{\prime \prime}$ phase, which is the main strengthening phase of $\mathrm{Al}-\mathrm{Mg}$-Si alloys. Needles of this kind were also observed in an artificially aged A356 alloy, and their appearance is obvious because the composition of the solid solution is very similar to the composition of the Al-Mg-Si alloys.

The second type of precipitates is represented by the cubic shaped plates marked as $\beta_{1}$. These precipitates are randomly distributed in the matrix, and have average dimensions of about $25 \times 25 \mathrm{~nm}$. An enlarged view of these precipitates is shown in Fig. 8a, with two separate particles marked $\beta_{1}$ and $\beta_{2}$. Thus, the morphology of these precipitates is a thin plate, and it can be identified as $\beta-\mathrm{Mg}_{2} \mathrm{Si}$ cuboid particles. EDX analysis of the cuboid particles showed that they are enriched by $\mathrm{Mg}$ and Si simultaneously, and this provides additional confirmation that these particles are an $\mathrm{Mg}_{2} \mathrm{Si}$ compound. It was reported by Fridlyander et al. 6 that the addition of Li decreases the solubility of $\mathrm{Mg}$ in $\alpha$-Al. Since L and B2 alloys contain $\mathrm{Li}$, this can be an additional factor for promoting the formation of cuboid particles.

The third type of precipitates is represented by the tetragonal shaped particles marked as $\delta^{\prime}$. Since both $\mathrm{L}$ and $\mathrm{B} 2$ alloys were alloyed with $\mathrm{Li}$, these precipitates can be identified as the $\delta^{\prime}-\mathrm{Al}_{3} \mathrm{Li}$ phase. These precipitates are formed along the (111) aluminum direction, and are fully coherent with the $\alpha$-Al matrix. The appearance of $\delta$ precipitates and the results of EDX analysis confirm that the $\alpha$-Al matrix in $\mathrm{Al}-\mathrm{Mg}$-Si alloys can be considered as a binary $\mathrm{Al}-\mathrm{Mg}$ alloy. The addition of Li promotes the formation not only of $\mathrm{Mg}$ and $\mathrm{Si}$ containing precipitates but also of the $\delta^{\prime}-\mathrm{Al}_{3} \mathrm{Li}$ phase.

Thus the presence of $\mathrm{Li}$ in a solid solution affects the formation of Mg-Si precipitates. Their heterogeneous behavior is linked to the association of $\mathrm{Mg}-\mathrm{Si}-\mathrm{v}$ (vacancy) with Li-v clusters. The preferential clustering of Li-v inhibits the cluster of $\mathrm{Si}$ and $\mathrm{Mg}$ atoms. It thereby retards the diffusion of $\mathrm{Si}$ and $\mathrm{Mg}$ atoms, and the precipitation of the needle-shaped $\mathrm{Mg}_{2} \mathrm{Si}$ phase is limited. The effect of the buffer for $\mathrm{Li}$ and $\mathrm{Mg}$ on the ageing kinetics leads to a slow increase in the $\mathrm{Mg}_{2} \mathrm{Si}$ and the $\mathrm{Al}_{3} \mathrm{Li}$ precipitates. 


\section{Conclusions}

(1.) The temperature peaks of a DSC evaluation of the $\mathrm{L}$ and $\mathrm{B} 2$ samples have the same behavior, but there is a considerable difference in the heat flow value. The eutectic melting temperature for the two alloys was near to $595^{\circ} \mathrm{C}$, demonstrating that the $\mathrm{Mg}$ content has no significant effect on the melting behavior of Al-Mg-Si alloys. A similar conclusion can be drawn for the addition of Li.

(2.) A higher solution treatment temperature leads to faster decomposition of eutectic lamellas into smaller segments, and to the spheroidizing effect. Homogenization equalizes the distribution of all elements in the grains. Artificial aging at a temperature of $175^{\circ} \mathrm{C}$ leads to the formation of strengthening particles, which increases the hardness and the microhardness of the $\alpha$-matrix.

(3.) The results were similar for the two alloys (L, LL) in the macro- and microhardness tests. The important point in this study is that after 120 minutes of artificial ageing all values decrease rapidly

(4.) The addition of lithium has a pronounced effect on the precipitation behavior in Al-Mg-Si-Mn alloys. TEM indicates that three types of precipitation - $\beta-\mathrm{Mg}_{2} \mathrm{Si}$ cuboid, $\beta^{\prime \prime}-\mathrm{Mg}_{2} \mathrm{Si}$ needle shaped and $\delta^{\prime}-\mathrm{Al}_{3} \mathrm{Li}$ tetragonal particle — are formed during artificial ageing.

\section{ACKNOWLEDGEMENTS}

Olena Prach gratefully thanks the Visegrad Fund for financial support. The authors would also like to thank doc. Ing. Jiří Cejp, CSc. and doc. Ing. Jiří Janovec, CSc. for their help with the tensile tests and with metallography, and Mgr. Maxim Puchnin for supervising the investigations presented here. Olena Prach would like to thank Oleksandr Trudonoshyn for helpful discussions. This work was supported by the Ministry of Education, Youth and Sport of the Czech Republic, program NPU1, project No LO1207.

\section{REFERENCES}

[1] H. Sternau, H. Koch, A. J. Franke, "Magsimal-59 an AlMgMnSi-type squeeze-casting alloy designed for temper F", (Aluminium Rheinfelden GmbH, P. O. Box 11 40, D-79601 Rheinfelden, Germany)

[2] Jiang X., He G., Liu B., Fan S., Zhu M., Microstructurebased analysis of fatigue behaviour of $\mathrm{Al}-\mathrm{Si}-\mathrm{Mg}$ alloy, in: Transactions of Nonferrous Metals Society of China, Vol. 2, 2011, 443-448 DOI:/10.1016/S1003-6326(11)60734-6

[3] Wu L., Ferguson G., Computer modeling of age hardening for cast aluminum alloys, in: Materials Science and Engineering, Vol. 4, 2009, 2-6 DOI:/10.1088/1757-899X/4/1/012014

[4] Mondolfo L.F. Aluminium Alloys: Structure and Properties. Butterworth \& Co Publishers Ltd; 2nd Revised edition, December 1979, 971

[5] Ohmori Y., Doan L.C., Nakai K., Aging process in Al-Mg-Si alloys during continuous heating, in: Materials
Transactions, Vol. 43, 2002, 246-255 https: //www.jim.or.jp/journal/e/pdf3/43/02/246.pdf

[6] Fridlyander I. N., Gryshko O.E., Berstnev V.V., Sheveliova L.M., Ivanov L.A., Influence of type structure on the properties of cold-rolled sheets of aluminum alloys, Light Alloys Technology, No 4, 2002, 4-14

[7] Petkov, T., Kunstner, D., Pabel, T., Kneibl, C., Schumacher, P. Optimizing the Heat Treatment of a ductile AlMgSi- alloy, Giesserei-Rundschau, Vol. 59, 2012, p. 194-200. http://www.voeg.at/upload/editor/File/archiv/ 2012/7-8/Giesserei_7_8_2012_Artikel(01).pdf

[8] Trudonoshyn O., Prach O., Boyko V., Mykhalenkov K., Selection and Optimization of Heat Treatment Process to Improve the Mechanical Properties of Casting Alloys of the Al-Mg-Si System, Casting Processes Kyiv 2013. № 4 (106), p. 12-21 http: //ptima.kiev.ua/index.php?option=com_content\& task=view\&id=304\&Itemid=56\&lang=ru\#link3

[9] RazaghianA., BahramiA., EmamyM., The influence of $\mathrm{Li}$ on the tensile properties of extruded in situ Al-15\%Mg2Si composite, Materials Science and Engineering A, 532 (2012) p.346-353

[10] Zhao Zhihao, Meng Yi, Cui Jianzhong, Effect of Mn on microstructures and mechanical properties of Al-Mg-Si-Cu-Cr-V alloy, China Foundry Vol.9 No.4, 2012, p.349-355

[11] Chakkrist Phongphisutthinan, Hiroyasu Tezuka, Tatsuo Sato, Semi-Solid Microstructure Control of Wrought Al-Mg-Si Based Alloys with Fe and Mn Additions in Deformation-Semi-Solid-Forming Process, Materials Transactions, Vol. 52, No. 5 (2011) pp. 834 to 841 http://www.jim.or.jp/journal/e/pdf3/52/05/ 834.pdf

[12] Trudonoshyn O., Mykhalenkov K., Morphology and properties of the primary Mg2Si crystals in the Al-Mg-Si alloys, Casting Processes Kyiv 2014. No 5 (107), p. 12-28

[13] R. Hadian, M. Emamyb, N. Varahram, N. Nemati, The effect of $\mathrm{Li}$ on the tensile properties of cast Al-Mg2Si metal matrix composite, Materials Science and Engineering A, № 490, 250-257, 2008. DOI:/10.1016/j.msea.2008.01.039

[14] S.-P. LI, S.-X. ZHAO, M.-X. PAN $\dagger$, D.-Q. ZHAO, X.-C. CHEN, O. M. BARABASH, Eutectic reaction and microstructural characteristics of $\mathrm{Al}(\mathrm{Li})-\mathrm{Mg} 2 \mathrm{Si}$ alloys. Journal Of Materials Science 36 (2001) 1569-1575 DOI:/10.1023/A:1017525520066

[15] Jian Zhang, Yu-qing Wang, Bing Yang, Effects of Si content on the microstructure and tensile strength of an in situ Al-Mg2Si composite, Journal of MATERIALS RESEARCH Vol. 14, No. 1, Jan 1999, p.68-74 DOI:/10.1557/JMR.1999.0012

[16] E. Georgatis, A. Lekatou, A.E. Karantzalis, H. Petropoulos, S. Katsamakis, A. Poulia, Development of a Cast Al-Mg2Si-Si In Situ Composite: Microstructure, Heat Treatment, and Mechanical Properties, Journal of Materials Engineering and Performance Volume 22(3) March 2013, p.729-741 DOI:/10.1007/s11665-012-0337-6

[17] Yongjin Wang, Hengcheng Liao, Yuna Wu, Jian Yang, Effect of Si content on microstructure and mechanical properties of Al-Si-Mg alloys, Materials and Design 53 (2014) 634-638 DOI:/10.1016/j.matdes.2013.07.067 